\title{
Medical Toxicology Education in a World of Limited Resources
}

\author{
Trevonne M. Thompson ${ }^{1}$
}

Published online: 27 May 2015

(C) American College of Medical Toxicology 2015

Poisoning is a worldwide problem. In 2004, an estimated 346, 000 people died from unintentional poisoning [1]. Ninety-one percent of those deaths occurred in low- and middle-income countries [1]. The World Health Organization (WHO) estimates that intentional pesticide ingestion accounts for approximately 370,000 deaths each year [1]. Both intentional and unintentional poisonings are dwarfed by snake envenomations. Recognizing that reliable data are difficult to obtain, the WHO estimates that approximately 5 million snake bites occur each year resulting in an estimated 2.5 envenomations and at least 100,000 deaths. This number does not include the numerous amputations and other permanent disabilities suffered by snake bite victims. The burden of poisoning on a global scale is huge.

Comparing these worldwide death data to the USA demonstrates a stark contrast. In 2013, the American Association of Poison Control Centers' National Poison Data System reported 2,188,013 human exposure cases that resulted in 1218 deaths [2]. The Centers for Disease Control and Prevention reported 6637 poisoning suicide deaths and 38,851 unintentional poisoning deaths in 2013 [3, 4]. The USA is the third most populous country in the world (317 million people) [5]. China has the largest population (1.35 billion); India is number two (1.25 billion) [5]. Despite being the third most populous country, the mortality and overall scope of poisoning in the USA are low compared to the rest of the world. The number of medical toxicologists in the USA is small compared to

Trevonne M. Thompson

thomps@uic.edu

1 Division of Medical Toxicology, Department of Emergency Medicine, University of Illinois at Chicago, $808 \mathrm{~S}$. Wood St (MC724), Chicago, IL 60612, USA other subspecialties, but this does not limit access to toxicology resources. Medical toxicology services are available to nearly all physicians and healthcare facilities in the USA via the poison control center system. Moreover, medical toxicology is a recognized subspecialty, and toxicology education is a part of the core curriculum for several primary specialties. There are many reasons why the burden of poisoning is lower in the USA - fewer venomous animals, better access to mental health and poison prevention resources, and the existence of a well-developed and modern healthcare system. Access to medical toxicologists and poison specialists, however, also play a role in the USA having lower poisoning death compared to other parts of the world where, in addition to limited resources, there may be limited expertise in managing poisoned patients.

The Global Educational Toxicology Uniting Project (GETUP) was developed as a way to begin meeting the needs of global toxicology education in areas with limited resources [6]. GETUP uses multiuser, web-based videoconferencing to connect healthcare facilities without access to medical toxicologists to those with access to medical toxicologists for the purpose of providing education. While still in its early stages, the importance of such collaborations is salient, especially to the locations receiving the education. Fiji, for example, was an early site for GETUP. I have personal experience in Fiji as a medical toxicologist, independent from GETUP. I recently spent time there observing and assessing the resources available to treat certain poisons. Fiji is a small, Pacific nation with limited resources and no regular access to a medical toxicologist or a poison information system. Access to a program like GETUP can provide the initial foundation for healthcare providers to develop a framework for poison management. That framework could then be used to develop a system of practice regarding poisoning treatment that is sustainable and maturable based on the resources available locally. GETUP 
cannot substitute for dedicated toxicology training but has the potential to be of great benefit. As GETUP matures, additional collaborations can develop. These collaborations have the potential to blossom into meaningful and sustainable relationships that could further develop toxicology education and even, perhaps, toxicology specialty training.

In medical toxicology, we can benefit from the experience of other disciplines in the area of global outreach and development. Cancedda et al. recently described their vast experience developing educational, clinical, and research collaborations in Rwanda [7]. To be successful, collaborations "must be driven primarily by the priorities of host institutions; build local capacity for training, research, and clinical care; and ultimately create value for the local population by improving the depth, breadth, and quality of health service delivery" [7]. GETUP cannot currently be expected to achieve all of those goals; it has not yet reached a level of maturity to do so. Instead, it can currently be used to place such goals in perspective and serve as a catalyst for future collaborations and developments.

Worldwide efforts to increase toxicology knowledge and resources, particularly in resource-poor areas, have the potential to affect the global burden of morbidity and mortality related to poisoning. GETUP is a step in that direction. Though still at an early juncture, there are many avenues GETUP could explore. In the short term, conducting evaluations of the current format and delivery methods could guide curriculum development of the videoconferences. In the long term, conducting formal needs assessments at sites receiving educational content from GETUP could inform future decisions about the scope, depth, and content of GETUP interventions and collaborations. In the end, the Global Educational
Toxicology Uniting Project may or may not be the final avenue toward meaningful interventions needed to affect poison care in the world. GETUP is, however, a good start and is laying the foundation for such interventions in the field of medical toxicology.

Funding There are no sources of funding for this manuscript.

Conflict of Interest The author declares that he has no competing interests.

\section{References}

1. World Health Organization. The global burden of disease: 2004 update. 2008. http://www.who.int/ipcs/poisons/en/.

2. Mowry JB, Spyker DA, Cantilena LR, Mcmillan N, Ford M. 2013 Annual Report of the American Association of Poison Control Centers: National Poison Data System (NPDS): 31st Annual Report. Clin Toxicol (Phila). 2014;52:1032-283.

3. Centers for Disease Control and Prevention. FastStats: accidents or unintentional injuries. http://www.cdc.gov/nchs/fastats/accidentalinjury.htm. Accessed 29 Apr 2015.

4. Centers for Disease Control and Prevention. FastStats: suicide and self-inflicted injury.http://www.cdc.gov/nchs/fastats/suicide.htm. Accessed 29 Apr 2015.

5. U.S. and World Population Clock. United States Census Bureau. http://www.census.gov/popclock. Accessed 29 Apr 2015.

6. Wong A, Vohra R, Ruha A-M, Koutsogiannis Z, Graeme K, Dargan PI, Wood DM, Greene SL. The global educational toxicology uniting project (GETUP): an Analysis of the first year of a novel toxicology education project. J Med Toxicol. 2015. doi:10.1007/s13181-0150479-7.

7. Cancedda C, Farmer PE, Kyamanywu P, et al. Enhancing formal educational and in-service training programs in rural Rwanda: a partnership among the public sector, a nongovernmental organization, and academia. Acad Med. 2014;89(8):1117-24. 